\title{
'I act this way because why?' Prior knowledges, teaching for change, imagining new masculinities
}

\author{
Lindsay Clowes
}

\begin{abstract}
This article begins by outlining some of the prior knowledges brought by undergraduate students to an introduction to gender studies class in the Women's and Gender Studies Department at the University of the Western Cape, South Africa. I show that, at the beginning of the course, students clearly understand gender to refer to women and femininity, imagining femininity (but not masculinity) to be responsive to social change. I suggest that, in the face of these prior knowledges, it is important to focus on masculinity as performance, as a cultural artefact and one that is deeply harmful to South African men. Student experiences of this teaching and learning suggest that it offers possibilities for imagining men as allies and beneficiaries - rather than enemies - in the struggle for gender equity.
\end{abstract}

\section{Introduction}

Men's violence is a global issue. But while it is possible to make such a generalisation it is also important to note that the particularities and scope of men's violent behaviours are rooted in time and place. In South Africa, men appear to be particularly quick to adopt extremely violent behaviours. The country has been identified as 'the most dangerous country in the world for women and girl children' (Joubert, 2007, p. 17) with South African men ranked 'as among the most violent in the world' (cited in Clowes, Lazarus, \& Ratele, 2010, p. 1). Claims about the high levels and wide scope of South African men's violence are reinforced almost daily by South African media, from reports about unprovoked attacks on an adult woman in the middle of a day in a Cape Town suburb to accounts of the rape and murder of teenagers and toddlers (Krever, 2014; Thorpe, 2014). The recent murders of Reeva Steenkamp and Anni Dewani playing out on an international stage as wells as the subsequent trials for murder of Steenkamp's boyfriend and Dewani's husband and co-accused (Clowes 2014; Gouws, 2014; Judge, 2013) have done little to disrupt dominant understandings of the ways in which - across communities - South African men regularly resort to violence.

While the headlines and media reports cited above might be dismissed, by some, as sensationalism in the pursuit of increased circulation figures by South African media, research tends to support claims that South African men are quick to employ violence. From a randomised controlled trial study on 1370 men aged 15 et al. (2006) reported that $16.3 \%$ of the participants admitted having raped a non-partner or participated in group 
rape, while $8.4 \%$ reported having raped an intimate partner. In another study, Jewkes, Sikweyiya, Morrell, and Dunkle (2010) reported that over a quarter (27.6\%) of the participants in a study of men in three districts in Eastern Cape and KwaZulu-Natal reported having raped a woman or girl (see also Jewkes, Nduna, Jama Shai, \& Dunkle, 2012; Seedat, Van Niekerk, Jewkes, Suffla, \& Ratele, 2009; South African Police Service, 2012; United Nations Office on Drugs and Crime, 2011).

Understandings of male violence as a major social problem in South Africa have been informed by feminist theorising that has drawn critical attention to the ways in which this violence is patriarchal violence, as an expression of sexism and male domination with deep roots in South African history. Research points to the ways in which particular patterns and expressions of contemporary violence are shaped and mediated by poverty and class, by institutionalised legacies of violence as well as by the acceptance of normative discourses that validate violence as a legitimate method of resolving conflict (Hassim, 2005; Madlala-Routledge, 2008; Morrell, Jewkes, \& Lindegger, 2012). Having their origins in histories of colonialism and imperialism, in racialized and gendered processes of industrialization, urbanisation, development and so on, these historical legacies are further complicated by the (deeply ironical) ways in which ideological and legislative commitments to the more socially just society articulated in the South African constitution of 1996 (Republic of South Africa, 1996) have themselves become implicated in violent behaviours, as debates around gender-based violence become framed as struggles over authentic African culture (Gouws, 2013; Ratele, 2013a). It is becoming increasingly clear, in other words, that resistance to and contestation of the more nurturant, egalitarian masculinities associated with gender equity are intimately interwoven with the very processes that produce violent behaviours in the first place.

Emerging over the last decade or so, a range of critiques offer insight into contestation of and resistance to behavioural change by South African men. Researchers have suggested that the limitations associated with including women in the formal institutions of state gender machinery, the lack of political will to combat male violence, and the role of 'tradition' are all useful in understanding the limitations of change (see for example, Gouws, 2008; Hassim, 2005; Ratele, 2013a, 2014). In terms of interventions and programmes funded (or underfunded) by the state, by global partners, through local businesses and through unpaid voluntary work, the most longstanding tend to be aimed at providing support to the women and girls who are the casualties of male violence. Rape Crisis and the Saartjie Baartman Centre in Cape Town examples of such organisations. An increasing volume of research has begun to foreground the importance of working with men and boys (see Shefer, Stevens, \& Clowes, 2010 for an overview), with such work also increasingly drawing attention to ways in which men - as well as women and children - are vulnerable to the behavioural dynamics of gender normativity in specific contexts. Against substantial evidence that South African men are victims as well as perpetrators of violence (Ratele, 2013b) interventions such as Sonke Gender Justice have increasingly involved boys and men (Greig \& Edstrom, 2012; Morrell et al., 2012; Stern, Peacock, \& Alexander, 2009).

But while this research, and these organisational and institutional interventions have and continue to do profoundly important work, it is evident that patriarchal violence 
remains a major social problem for everyone in contemporary South Africa. And thus, in evaluating the work aimed at understanding, informing and contributing to developing less violent behaviours by South African men, Kopano Ratele (2014) concludes that it has 'underachieved' and 'gone down a blind alley' (this volume). Ratele suggests that we need to reflect on how and why South African men are resistant to the more nurturing behaviours required by gender equity. If, as he and Mbuyiselo Botha have suggested (2014), it is access to financial resources that is central to what makes a man powerful or subordinate, then to offer gender equality in contexts of poverty and unemployment is in fact to offer very little. This needs to be taken seriously because they are suggesting that the 'blind alley' is structured around the same historical legacies and contemporary experiences of subject locations structured around gender, race and class, culture and tradition, age and religion, ethnicity and sexuality, etc. that are implicated in processes of violence (Gouws, 2013; Moffet, 2006; Morrell et al., 2012; Ratele, 2014; Ratele, forthcoming this volume). It is, in other words, what we imagine the concept 'man' to mean, that both underpins the violence and mitigates against change.

This paper reflects on some of the meanings of the concept 'man' made by undergraduate students through an exploration of prior knowledges brought to an introduction to gender studies class at the University of the Western Cape, South Africa. The vast majority of the undergraduate students who enter my classes appears to understand men through biology as 'simply bodies', while at the same time, because of the complex and contradictory ways in which the social locations of dominance are unmarked, also understanding them as absent and without bodies (Hearn, 2014). I suggest that, in as much as they can be considered to highlight aspects of the communities from which my students come, these prior knowledges are an important element in understanding the intractability of resistance to change in men's behaviour. Our inability to unsettle entrenched knowledges, reflected in resistance to behavioural change, is, in a sense, a widespread failure of the imagination. In this paper I draw on reflections of teaching and learning over the last three years to suggest that feminist teaching presenting challenges to these prior knowledges offers students what Megan Boler (2013) describes as 'critical hope' - new ways of imagining 'men' and the behaviours associated with signalling masculinity, ways that are more nurturant and less violent.

In the discussion that follows I draw on my experiences of teaching a second-year introduction to gender studies course as well as students' experiences of learning since 2013. The first point to note is that the teaching undertaken in the Women's and Gender Studies Department aims to contribute to social change and to promote social justice through the production of critical citizens. The Department does not offer first-year courses and there are no pre-requisites for this course. Thus, while some students may have encountered key concepts emerging out of feminist theory in other courses during their first year of study, there are others who might be engaging with feminist theory for the first time. This matters because the teaching and learning undertaken in the course aspires to be student centred, and so an exploration and acknowledgement of the prior knowledges brought by students has been central to the design of the course since 2012.

As noted by Ausubel as far back as 1963, '[t]he most important single factor influencing learning is what the learner already knows; ascertain this and teach him/her 
accordingly' (cited in Hay, Kinchin, \& Lygo-Baker, 2008, p. 302). Establishing what it is that students bring to the course is important precisely because prior knowledge is the 'baseline from which learning can be calculated and its quality assessed' (Hay, Kinchin, \& Lygo-Baker, 2008, p. 300). It is important as well because meaningful learning is further facilitated if misunderstandings and misconceptions are identified and addressed early on, and if concerns relevant to students inform the debates and discussions of concepts and theorising that are central to the course.

With this in mind, the classes in the first six weeks of the module have, over the past three years, begun with a 'quick quiz'. The questions posed are simple, with no right or wrong answers. Answering them is voluntary, anonymous and does not count for marks: I have no way of knowing who has responded and who has not, or of tying answers to individuals. In any one class about $75 \%$ of the students present generally submit an answer. Since 2012 the question posed in the very first class has been the same - to write down the first three words that come into your head when you hear the word 'gender'.

The vast bulk of the students overwhelmingly choose the same few words every year, offering 'women', 'female' 'equality', 'stereotypes', 'inequality', 'oppression', 'discrimination' far more frequently than words such as 'male' or 'men'. In 2014, the second class began with the question 'whose lives have changed the most over the last couple of hundred years? Men or women's or both? And in what ways?' In 2015, the second class saw students asked to list the first three words that came into their heads when they heard the word feminist, and the question of whose lives had changed the most was only asked in the third class. Before they answer any of these questions, students are advised that their (anonymous) responses will be collated and used for educational purposes, usually in the following class but sometime later in the course, as well as for research purposes. Some of the data presented below emerge out of these quick quizzes.

Another aspect to student-centred learning is the emphasis on student ownership of the learning process. There are, for example, three different ways of earning marks in this course that contribute to a continuous assessment mark. Students are free to choose between joining small group tutorials, submitting online worksheets or participating in an online discussion forum, or any mix of these three activities. Students are advised that extracts from the online discussion forum may be used for teaching purposes - for instance, all the exam questions were drawn from the debates on this forum in 2015 - as well as for research purposes. Where extracts from some of the conversations that took place on the online discussion forum are presented in this article, names have been changed to guarantee anonymity. In addition, the paper also offers observations made by students in response to two anonymous online surveys exploring learning experiences conducted half way through the course and again at the end of the course. Finally, towards the end of 2013 two focus group discussions aimed at exploring student experiences and understandings of the focus on masculinities were held with a group of male students and a group of female students, respectively. Participation in these discussions was voluntary, confidential, and students were advised that they were free to withdraw at any time. Where extracts from these conversations have been cited in this article, names have been changed to protect confidentiality and anonymity. 


\section{Prior knwoledges}

As observed earlier, evidence from the short answers submitted by students in the first class of the course suggests that they start the course with very clear understandings of gender as a concept referring primarily to women and ways in which women (as opposed to women and men) are unequally positioned in society. Three words ('women', 'female' and 'equality') stand out in particular for being the most commonly offered by students over the last three years. The impression that students' understand gender to refer primarily or mainly to women and to change in women's (in contrast to women's and men's) lives is further reinforced by their answers to another 'quick quiz' question asked for the first time in 2014 about whether it was men's or women's (or both) lives that have changed the most in the last couple of hundred years? In each year, as indicated by the following selected examples, it was just four students (out of 54 who responded in 2014 and 51 who responded in 2015) who thought that both men's and women's lives had changed:

Both. If either's lives have changed then the other is naturally affected. (2014)

Both. Men have become less dominant and women have become less submissive. (2014)

Both. Women have more rights and some men understand that women are not born to carry children and do housework. (2015)

Both. Women can now to 'men's jobs like mechanical engineering and plumbing, and men can take care of the children and cook etc. (2015)

Both. Women have had structural changes in roles, men have seen acceptance of changes in sexuality. (2015)

Both. As women have acquired legal rights and equal work, men's work has changed. (2015)

Students with these views were in the minority in both 2014 and 2015, with the vast majority - over $80 \%$ - of students who responded agreeing that it was women's lives that had changed the most. In 2014, 45 (of 54) students stated that they believed women's lives to have changed the most. They pointed to a range of factors to support their position:

Women are more empowered nowadays and are taking on the roles of men in terms of the economy.

Women are more independent have more power, are leaders, managers and heads of households.

Women are not merely seen as housewives anymore but as equals able to work.

Women have become more liberal and less oppressed.

Women are now allowed to dress in any fashion they desire ... can occupy the same jobs as men.

Women have made phenomenal progress with regards to freedom from oppression. Women have earned more respect, more independence, can study to become someone.

The following year, 2015, saw a similarly high proportion of students (46 of 51) offer a similar perspective with similar supporting evidence: 
Women don't have to stay home anymore ... women aren't dependent on men anymore. Women are free to pursue their own dreams and goals.

We now occupy boardroom seats, lead global multimillion companies. Women are recognized and appreciated ... treated as equal to men.

Women are recognized as individual beings, not just part of the family expected to quietly obey and not think.

Women can wear pants now, go to school, be in top managerial positions, but are also more vulnerable to rape and abuse and other vicious attacks.

Women don't have to be mothers but are highly sexualized.

Women have come forward in the business world and taken charge. Women, because of their strong entry into the workforce.

Women's mindsets have changed, men's mind sets haven't changed.

Women have more opportunities to be in higher positions

Women today stand up for themselves, they have agency, are empowered, have a voice.

What we can draw from this is that gender equality rights, campaigns and policies appear to be working in changing in a positive direction the views of our students about women's capabilities. Although at least two students drew attention to changes understood to be negative, noting that women were more highly sexualized and more vulnerable to sexual attacks, the overwhelming majority of answers pointed to what appear to be understood as positive change. Women, these students insisted, had made 'progress' and were no longer subordinate partners to men either in the workplace or the home. Women could now work alongside men as equals and even as leaders. Their answers suggest that most of my students understand women today to be more independent and to have substantially more choice than in the past about how to live their lives. Implicit in these answers, I suggest, is an understanding in the minds of these students that - for women - biology is not destiny. Or, perhaps more accurately, that biology is no longer destiny for women. One student states quite clearly that women no longer have to be mothers, while others suggest that women are no longer defined or constrained by domestic obligations. If students understand women to have more choices now, they must simultaneously understand women to have had fewer choices in the past. And if students understand women today as able to act on these choices then it suggests that they understand the behaviours associated with femininity to be responsive to changing contexts, as social rather than biological constructs.

At the same time, while most agreed that it was women's lives that had changed, there were a few dissenting voices, with five students in 2014 and just one in 2015 explaining that it was men's lives that had changed the most, that:

Men still hold top positions but women are moving into these jobs. This striving for equality affects men who are expected to be powerful main sources of income. (2014)

Men, with women gaining more rights and being able to have more dominant roles in society men's lives changed because they only then realized who is really in control. (2014)

Men, because it seems they had much more power were much more in control. (2014) Men, in terms of power relations and the amount of opportunities they get in relation to women. (2014) 
Men have a lot more opportunities over the years than women, women are still oppressed and looked down upon. (2015)

It might seem from these latter responses that there is some disagreement about whether it is men's or women's lives that have changed the most. More careful analysis suggests that there is a great deal of commonality in students' understandings of gendered change. There is, for example, a sense in which the more distant past is marked by the absence of change, that distant human history is a history of women's subordination and male domination that, until recently, transcends time and place - and that what has changed recently has been women's behaviour. Another feature that stands out is the way in which, in contrast to women, men are positioned as passive, impacted on by social change, rather than agentic. Where women - today - appear to be understood primarily through the social, men tend to be understood as 'simply bodies' struggling with social change, rather than themselves products of or agents of social change. If in the light of these answers, we consider once again students' suggestions that gender means 'women', 'equality' and 'female', then perhaps it can be argued that a key gender difference, in the prior knowledges brought to class, is that women are gendered and men are not (see Dover, 2014).

\section{Responding to prior knowledges}

Since 2011, the second year introductory course has increasingly focused on questions of masculinity and this has begged a number of questions. Established in 1995, for instance, the Women's and Gender Studies Department (then programme) is itself the product of broad struggles for gender equality in South Africa as well as on campus. Should a space originally designed to foreground women's experiences and women's voices be focusing on men and masculinities? And if so what is the place of men and men's studies in gender studies? To what extent does such a focus risk reinscribing masculinity as the unmarked default and/or depoliticizing or diluting the political agenda of a feminist agenda? Does such a focus pose a danger, as Shefer and Aulette (2005, p. 107) asked a decade ago, of the historical domination of men 'as both subjects and objects of knowledge production ... reemerging to usurp and destabilise women's studies?' (see also Berila, Keller, Krone, Laker, \& Myers, 2005). While such considerations should not be lightly dismissed, it is my conviction that a key objective of a feminist teacher is to challenge dominant understandings and normative discourses, and that given the prior knowledges outlined above a critical focus on masculinities is both legitimate and desirable.

At the same time, it is important to acknowledge that such a focus generates a range of challenges. These are built, in part, around the circulation of dominant discourses and the ays in which these are expressed, experienced, challenged and resisted by students. As Megan Boler has observed, in considering the ethics of shattering world views, each new semester brings three groups of students - those who find their world views shattered but remain engaged in 'rebuilding a sense of meaning and coherence in the face of ambiguity', those who appear disaffected 'already sufficiently numb so that my attempts to ask them to rethink the world encounter only vacant and dull stares', and those who 'angrily and vocally resist' any attempts to think critically about the world (Boler, 2013, p. 27). Populist stereotypes of feminism and feminist teaching as anti-men are deeply implicated in the last set of responses, reactions which have lead Boler and Michalinos Zembylas to think critically about the challenges and opportunities involved in requiring students to engage in 
critical self-reflection and inquiry regarding their cherished beliefs, deeply held assumptions and value systems in ways that destabilise their understandings of themselves and their worlds (see Boler, 1999; Boler \& Zembylas, 2003). That such resistance is regularly encountered by educators of and for social justice in the North is testified to by the expansion of research reflecting on the challenges of teaching masculinities to young men and women, with, for example, a special edition of Women's Studies focusing on 'Men and masculinities in Women's Studies' appearing in 2013 (Farr, 2013).

Stereotypes of feminism and feminists as anti-men are complicated in post-colonial societies in general and Southern Africa is no exception to this. These complications both frame and underpin the possibilities for effective teaching. In the first place, feminist theory is itself popularly understood as a Western import, as unAfrican. Second, 'race' has been the dominant explanatory narrative of South African history, with struggles and conflicts that had acknowledged complex and intersecting subject locations structured around class, gender, ethnicity, religion and so on becoming increasingly more narrowly defined as conflict over primarily racial (and class) inequalities over the course of the twentieth century. Over the second half of the century, in challenging white monopolies over truth, a new generation of South African activists further foregrounded racial inequalities in a struggle predicated on the necessity of a psychological transformation within the minds of black South Africans. Today these long histories foregrounding 'race' continue to underpin and inform powerful discourses through contestations over 'authentic' African culture in which patriarchal behaviours are positioned as more (and egalitarian behaviours positioned as less) authentic. That teaching for diversity in contemporary South Africa continues to foreground 'race' gender, sexuality, religion ethnicity, and so on underlines just how powerful racial discourses are and does little to highlight the possibilities of feminist approaches to social justice (Clowes, 2013b). Emerging from all of this then is a popular understanding of feminism in South Africa as not simply unAfrican and anti-men but as very specifically anti-African men.

These popular understandings and prior knowledges inform the demographics of the student body in that less than 10\% of the students in the Women's and Gender Studies Departments at both the University of the Western Cape (and its close neighbour the University of Cape Town) are young men. They also frame and underpin the possibilities for effective teaching and learning in feminist South African classrooms (see, for example, Bozalek, Carolissen, \& Liebowitz, 2013; Macdonald, 2013; Pillay, 2012). At the same time, given the prior knowledges outlined earlier, a critical focus on men and masculinities means finding ways to teach that challenge, rather than reinforce, understandings of feminism as anti-black men and finding ways to facilitate learning that evade the trap of serving as nursemaid or caretaker to students, whether male or female, who might feel threatened by a critical focus on gendered cultures.

As bel hooks (2004) and others have noted, one route through these tensions is through teaching that foregrounds patriarchy, rather than men, as the problem, teaching that foregrounds ways in which patriarchy is in fact deeply harmful to young men. It was with this in mind that the course was redesigned in 2011 to explore the relevance, for 
South African men, of hooks' (2004, p. 66) point that the 'first act of violence patriarchy demands of males is not violence towards women' but 'psychic acts of self mutilisation'.

Writing by international theorists was complemented by local researchers as well as more accessible locally generated material such as newspaper and magazine articles. The overarching focus was to draw on this theorising to consider whether and in what way local patriarchies might be 'bad news' for South African boys and men (Hearn, 2007, p. 17). I was astonished at the end of the course when 58 (out of 60) students who chose to answer a question asking about the ways in which gender equity might benefit men wrote instead about how gender equity would benefit women. It appeared, after an entire semester of focusing on how contemporary performances of masculinity were harmful to South African men, that the notion that gender equity might have something to offer men remained either unsayable or unthinkable or both (Clowes, 2013a).

In 2012, having reflected on the limited achievements of 2011, the critical focus on masculinities was further developed and refined such that only minor changes, or changes to, e.g., assessment practices, have taken place in the teaching and learning that is reflected upon in this paper. Since 2012, students have been offered theorising that challenges simplistic dualisms structured around sex, gender and sexuality. These are supplemented by more accessible materials such as documentaries, digital stories, newspaper and magazine articles offering critical insights into the complexities of contemporary performances of South African masculinities. A series of guest speakers from Gender Dynamix (a South African NGO working on transgender experiences) as well as Sally Gross (an intersex activist who had lived the first 40 years of her life as a catholic priest) and by Patrick Godana of Sonke Gender Justice (a South African NGO working with boys and men to promote gender equality) further challenged normative understandings of what it meant to be a man.

\section{Unsettling prior knowledges}

Given a key aim of the teaching and learning was to challenge prior knowledges, what evidence is there that the normative discourses around gender outlined earlier have indeed been unsettled? And to what extent has any unsettling involved new ways of imagining the self and the future? Both male and female students had expected an introduction to gender studies course to focus on women, and in the focus groups conducted towards the end of the course in 2013 several expressed their surprise that this had not been the case:

I thought that gender was going to be about women because it's Women and Gender Studies. (Thabo FG2)

I thought it will help in my psychology studies to the point that it will describe how women - how females and males differ in how they think and ways like that. (Arno FG2)

At first, before I did [the course] I was always thinking men, women, separated. (Zane FG2) 
I've identified as a feminist for a long time, but I really had not given much thought into masculinity as a gender, as much as I had given femininity as a gender ... like before I thought that it was about women reaching equality with men. (Ntombi FG1)

Understandings that gender refers primarily to women and girls are widespread (see Clowes, 2013a; Dover, 2014), and such understandings certainly underpinned student expectations of the course. The realisation that gender refers to more than just women, that it can refer to relationships between men as well as between men and women thus demonstrates the disruption to prior knowledges brought to class. This new understanding is further underlined through students drawing attention to their realisation that contemporary practices of patriarchal masculinity were harmful to men:

I doubt that I can ever forget or discard what I learned ... about masculinities and how this patriarchal society that we live in is detrimental to men's health. (Anonymous online survey 2013)

The multiple ways that patriarchy hurts men! That masculinity too is a gender, in every way that femininity is. (Anonymous online survey 2013)

I enjoyed immensely the visit from the Sonke Gender Justice people where they came and talked to us about the work that men are doing to embrace gender equality and teaching other men and boys the value that would come out of that. That patriarchy is not all rosy for men, that patriarchy hurts men in many ways. So I loved that, I feel like it has strengthened my own conviction in why I believe in gender equality ... now it's, it's everyone stands to benefit from it. (Alice FG1)

The corollary to understanding that that patriarchy is harmful to men is an awareness that gender equity is about more than women obtaining the same privileges that have always been available to men, that men are equally embedded in gender systems, implicated in and subjects of systems of power, expressions of gendered cultures (Lorentzen, 2011). Alice, for example, has clearly begun to imagine the possibility that men might also be beneficiaries of gender equity.

Understandings of patriarchy as a problem for men as well as women, and the challenges for men of trying to live up to normative masculinities, opened up the possibility, for some students at least, that men might not be the enemy (hooks, 2004) as well as the possibility that men might have important roles to play in contributing to change:

My perspective has changed a lot about men, and that men are not all that bad even if I disagree with some of their actions. (Anonymous online survey 2013)

Doing the interview ... helped me to know more things about men. Also knowing that there are men feminists and how important it is for men to be feminist. (Anonymous online survey 2013) 
I am very happy to hear from the Sonke group, I actually wish to have my father, brother, grandfather, fiance, etc. to get to hear that there are men trying their best to actually make a change ... These men of Sonke have been through a lot and you would take them for aggressive and angry, but yet they stand in front of us today, totally humbled and open. (Chante online discussion forum 2013)

What was noteworthy about his learning, Thabo suggests, was a growing awareness of masculinity as a cultural artefact that could be explored, critiqued and considered:

Yes I was [surprised]. Masculinity and umm, patriarchy, I was - you know it's always been there but you've never actually noticed that that's how society works ... it was an eye opener. (Thabo FG2 2013)

Arno made a similar point:

You're conditioned in a certain way when you are brought up ... like your family's norms and morals ... you tend to overlook things ... until someone opens your eyes to it ... same as this, you didn't realize that you know men are allowed to do so many things which you take for granted because that's supposedly how it is, especially because a lot of religions and cultures dictate it like that. So when it's actually put in front of you and say listen but look at this you know ... I think it opens your eyes to it. (Arno FG2 2013)

Both Thabo and Arno insisted that they had become more aware of masculinity as a social construct, both had, in other words begun to recognise some of their own 'inscribed habits of emotional inattention' (Boler, 2013). Rather than a simple product of human biology Arno indicated that he now understood masculinity as an expression of power complexly interwoven with and mediated by other constructs such as class, race and culture. Now he sees masculinity as:

something that's obvious, but I didn't think of it ... not all masculinities are the same. It depends on your culture, your race or your even your demographic or social status ... Now I've sort of come to a realisation ... masculinity is all about the power, the authority ... So I think that's what it comes down to authority and power figures. (Arno FG2 2013)

Thabo also foregrounded social factors such as class and race rather than biological factors in his explanation of how he understood masculinity. Rather than an essentialised identity emerging out of male biology, Thabo explained that:

Race plays a part in masculine behaviour. I don't know if you understand, because for a black person masculinity is different, for a white person it's different, for a coloured ... even in class you see like, if you look around in class, you see oh yeah, he's wearing like that and you know I'm wearing this and I've got these values and he's got those values. (Thabo FG2 2013)

Applying the insights he had developed, Arno drew attention to the rocky marriage of an unemployed friend who was being supported by his wife, suggesting that his friend's 
inability to live up to the socially constructed ideal had created a social vulnerability that was expressed through aggression:

I've realised ... him not having a job, it undermines his masculinity and that's why he's so sensitive you know, he can't provide ... and we've been conditioned to think this is how we have to act and he's unable to act that way so that's why probably he's got all this aggression. (Arno FG2 2013)

Finally, engaging with the idea of masculinity as learned (and harmful) performance rather than an automatic preordained script prescribed by human biology saw Arno begin to consider some of the ways in which he was situated within relationships of privilege and marginality as well as the ways in which he might reproduce these relationships. In beginning to pay more attention to the 'inscribed habits of inattention' (Boler, 2013),

Arno begins to consider that change is possible, to imagine the possibility that he (and presumably other men) might behave differently:

It makes you realize, you know, how petty it is when you, you think we have to act this way, ... you are being, someone else's ideologies is imposed upon you to act a certain way instead of acting in a natural way you know, and that's gone so far now that our natural way of acting is in this specific way. And it makes you think you know, I act this way because why? (Arno FG2 2013)

\section{Conclusion}

As a white middle-class feminist educator 30 or more years older than most of my undergraduate students, I have limited understanding of what it means to be a young, gendered and raced person in contemporary South Africa. The knowledges and understandings that I bring to class - and that underpin course design - are very different to those of my students. And so it is important to establish the knowledges brought by students because effective learning is structured around what they already know, around the practices and behaviours - including male violence - they have learned to take for granted in the communities from which they come. As observed at the beginning of this paper, it is violence against women, children and other men heteropatriarchal violence - that is so problematic and that is so resistant to change. The reasons for this are clearly complex and linked to a range of factors including poverty and social inequalities structured around gender and other salient subject locations, the lack of political will, as well as normative discourses in which violence is a legitimate method of resolving challenges to heteropatriarchal authority. They are also linked to essentialised understandings of what it means to be a man, meanings which legitimise violence while simultaneously foreclosing the possibility of change.

Taking these knowledges seriously over the last three years has revealed some of what Boler (2013, p. 30) calls the 'inscribed habits of emotional inattention', to point to ways in which at the beginning of an introduction to gender studies course the behaviour of men (but not women) tends to be essentialised, unmarked, understood through biology as fixed and unchanging by the vast majority of the students who have signed up for the course. While one must be careful in extrapolating the prior knowledges held by students 
to the communities from which they come, the understandings students bring must be representative on some level of the wider discourses operating in society, discourses that contribute to the maintenance of heteropatriarchal violence. The prior knowledges revealed by my students show just how deeply embedded these cultural habits of seeing - and not seeing - have become, how even though they are social and cultural as much as they are personal, these habits 'come to feel like one's chosen self-identity' (Boler, 2013, p. 30). Challenging these habits of attention and inattention are a central aim of the course, and that this is experienced as deeply challenging is underlined by the swift agreement from a range of students when someone commented on the online discussion forum in 2014 that the course 'should come with a health warning.'

On the one hand then, while the vast majority of young women (and the tiny minority of young men) who signed up for this course over the last three years did so because they were interested in questions of gender, they expected the course to focus on questions of femininity and women's empowerment. Such a course could very easily have been put together. Undermining these expectations, however, by introducing students to theorising that challenges normative understandings presents possibilities for imagining men and masculinities in different ways. And yet, as Ratele (2013b) observes, such understandings gain little or no traction in broader discourses. One component of an explanation for this can be found, I suggest, in the prior knowledges discussed above, knowledges that are further underlined by the skewed ratio of female to male students in such courses. That the vast majority of young men are able to self-select out, are never systematically exposed to the idea that masculinity is a performance of gender that is just as fluid and flexible as femininity means that far too many students - the leaders of tomorrow - will continue to see patriarchy as women's problem and gender equality as irrelevant for men. Unless we find ways of foregrounding and critiquing these prior knowledges more broadly, feminist educators and activists risk re-inscribing the very discourses (and violent behaviours) that are so resistant to change.

\section{Acknowledgements}

Thanks to Kopano Ratele and Jeff Hearn for comments on an earlier version of this paper.

\section{Funding}

This work is based on research supported by the National Research Foundation. Any opinion, findings and conclusions or recommendations expressed in this material are those of the author and therefore the NRF does not accept any liability in regard thereto.

\section{Disclosure statement}

No potential conflict of interest was reported by the author.

\section{Notes on contributors}

An historian by training, Lindsay Clowes is an Associate Professor in the Women's and Gender Studies Department of the University of the Western Cape. She writes about gender, men and masculinities and has a current research focus on teaching gender. 


\section{References}

Berila, B., Keller, J., Krone, C., Laker, J., \& Myers, O. (2005). His story/her story: A dialogue about including men and masculinities in the women's studies curriculum. Feminist Teacher, 16(1), 34-52.

Boler, M. (1999). Feeling power: Emotion and education. New York, NY: Routledge.

Boler, M. (2013). Teaching for hope: The ethics of shattering world views. In V. Bozalek, B. Liebowitz, R. Carolissen, \& M. Boler (Eds.), Discerning critical hope in educational practices (pp. 26-39). Abingdon: Routledge.

Boler, M., \& Zembylas, M. (2003). Discomforting truths: The emotional terrain of understanding difference. In P. Trifonas (Ed.), Pedagogies of difference: Rethinking education for social change (pp. 110-136). New York, NY: RoutledgeFalmer.

Bozalek, V., Carolissen, R., \& Liebowitz, B. (2013). A pedagogy of critical hope in South African higher education. In V. Bozalek, B. Liebowitz, R. Carolissen, \& M. Boler (Eds.), Discerning critical hope in educational practices (pp. 44-54). Abingdon: Routledge.

Clowes, L., Lazarus, S., \& Ratele, K. (2010). Risk and protective factors to male interpersonal violence: Views of some university students. African Safety Promotion Journal, 8(1), 1-18.

Clowes, L. (2013a). The limits of discourse: Masculinity as vulnerability. Agenda, 95(27.1), 12-19.

Clowes, L. (2013b). Teacher as learner: A personal reflection on a short course for South African university educators. Teaching in Higher Education, 18, 709-720.

doi:10.1080/13562517.2013.836094

Clowes, L. (2014). Dewani, Pistorious: Patriarchal masculinity on trial in SA. Retrieved from http://www.thoughtleader.co.za/lindsayclowes/2014/05/15/dewani-pistorius-patriarchalmasculinity-on-trial-in-sa/

Dover, P. (2014). Gender and development cooperation: Scaling up work with men and boys. IDS Bulletin, 45(1), 91-98. doi:10.1111/1759-5436.12073

Farr, D., (Ed.). (2013). Men and masculinities in women's studies. Special issue of Women's Studies, 42(5), 483-628.

Gouws, A. (2008). Obstacles for women in leadership positions: The case of South Africa. Signs, 34(1), 21-27 doi:10.1086/588486

Gouws, A. (2013). Multiculturalism in South Africa: Dislodging the binary between universal human rights and culture/tradition. Politikon: South African Journal of Political Studies, 4O(1), 35-55. doi:10.1080/02589346.2013.765674 
Gouws, A. (2014). Anene Reeva frenzy reveals a nation's shallowness. Retrieved from http://www.thoughtleader.co.za/amandagouws/2013/02/25/anene-reeva-frenzy-reveals-anations-shallowness/

Greig, A., \& Edstrom, J. (2012). Mobilising men in practice: Challenging sexual and gender based violence in institutional settings. Brighton: Institute of Development Studies.

Hassim, S. (2005). Voices, hierarchies and spaces: Reconfiguring the women's movement in democratic South Africa. Politikon: South African Journal of Political Studies, 32, 175-193. doi:10.1080/02589340500353417

Hay, D. B., Kinchin, I. M., \& Lygo-Baker, S. (2008). Making learning visible: The role of concept mapping in higher education. Studies in Higher Education, 33, 295-311.

Hearn, J. (2007). The problems boys and men create, the problems boys and men experience. In T. Shefer, K. Ratele, A. Strebel, N. Shabalala, \& R. Buikema (Eds.), From boys to men: Social constructions of masculinity in contemporary society (pp. 13-32). Lansdowne: UCT Press.

Hearn, J. (2014). Men, masculinities and the material(-)discursive. NORMA: International Journal for Masculinity Studies, 9(1), 5-17.

hooks, b. (2004). The will to change: Men, masculinity and love. Washington, DC: Square Press.

Jewkes, R., Dunkle, K., Koss, M. P., Levin, J. B., Nduna, M., Jama, N., \& Sikweyiya, Y. (2006). Rape perpetration by young, rural South African men: Prevalence, patterns and risk factors. Social Science and Medicine, 63, 2949-2961.

Jewkes, R., Nduna, M., Jama Shai, N., \& Dunkle, K. (2012). Prospective study of rape perpetration by young South African men: Incidence \& risk factors. PLoS ONE, 7(5), e38210. doi:10.1371/ journal.pone.0038210

Jewkes, R., Sikweyiya, Y., Morrell, R., \& Dunkle, K. (2010). Why, when and how men rape: Understanding rape perpetration in South Africa. South African Crime Quarterly, $34,23$.

Joubert, P. (2007, November 16-22). Men who speak with fists. Mail and Guardian. 17.

Judge, M. (2013). Behind the shock and awe the violence is normal. Retrieved from http://www.thoughtleader.co.za/melaniejudge/2013/04/03/behind-the-shock-and-awe-theviolence-is-normal/

Krever, M. (2014). The end of innocence: Photojournalist documents child sexual abuse. Retrieved from http://amanpour.blogs.cnn.com/2014/o2/26/the-end-of-innocence-in-southafrica-children-raping-children/ 
Lorentzen, J. (2011). Masculinities, power and change. NORMA: Nordic Journal for Masculinity Studies, 6(2), 110-123.

Macdonald, H. M. (2013). Inviting discomfort: Foregrounding emotional labour in teaching anthropology in post-apartheid South Africa. Teaching in Higher Education, 18, $670-682$.

Madlala-Routledge, N. (2008). We need an international campaign to resist androcentric militarized neo-colonial masculinities! Feminist Africa, 10, 85-90.

Moffet, H. (2006). 'These women they force us to rape them': Rape as a narrative of social control in post apartheid South Africa. Journal of Southern African Studies, 32(1), 129144 .

Morrell, R., Jewkes, R., \& Lindegger, G. (2012). Hegemonic masculinity/masculinities in South Africa: Culture, power, and gender politics. Men and Masculinities, 15, 11-30.

Pillay, M. (2012). Challenging patriarchal masculinity in act like a lady. Think like man: A feminist theoretical perspective. In J. Claassens \& S. Viljoen (Eds.), Sacred selves: Essays on gender, religion and popular culture cape town (pp. 81-100). Stellenbosch: Griffel.

Ratele, K. (2013a). Masculinities without tradition. Politikon: South African Journal of Political Studies, 4O(1), 133-156.

Ratele, K. (2013b). Subordinate Black South African men without fear. Cahier d'Etudes Africaines, 209-210, 247-268.

Ratele, K. (2014). Currents against gender transformation of South African men: Relocating

marginality to the centre of research and theory of masculinities. NORMA: International Journal for Masculinity Studies, 9(1), 30-44. Retrieved from http://dx.doi.org/10.1080/18902138.2014.892285

Ratele, K. (2015). Location, location, location: Reckoning with margins and centres of masculinities research and theory in an inter/trans-national South Africa-Finland project on youth. NORMA: International Journal for Masculinity Studies, 10(2), 105116.

Ratele, K., \& Botha, M. (2014). Capitalism has emasculated black men. Retrieved from http://www. iol.co.za/sundayindependent/capitalism-has-emasculated-black-men1.1703727\#.VX_kDvmqqko 
Republic of South Africa. (1996). Constitution of the Republic of South Africa Act, No. 108 of 1996. Cape Town:Author.

Seedat, M., Van Niekerk, A., Jewkes, R., Suffla, S., \& Ratele, K. (2009). Violence and injuries in South Africa: Prioritising an agenda for prevention. The Lancet, 374, 10111022.

Shefer, T., \& Aulette, J. (2005). Doing gender in South African universities:

Reflections on a research forum celebrating ten years of women's and gender studies at UWC. Feminist Africa, 5, 105-111.

Shefer, T., Stevens, G., \& Clowes, L. (2010). Men in Africa: Masculinities, materiality and meaning. Journal of Psychology in Africa, 20, 511-518.

South African Police Service. (2012). An analysis of the national crime statistics: Addendum to the annual report 2011/2012. Annual report. Pretoria: Author.

Stern, O., Peacock, D., \& Alexander, H. (2009). Working with men and boys: Emerging strategies from across Africa to address gender-based violence and HIV/AIDS. Cape Town: Sonke Gender Justice \& Men Engage.

Thorpe, J. (2014). A deep dip in everyday racism/classism/sexism etc. Retrieved from http://www. thoughtleader.co.za/jenniferthorpe/2014/10/22/a-deep-dip-in-everydayracismsexismclassismetc/

United Nations Office on Drugs and Crime, Statistics and Surveys Section, Division for Policy Affairs. (2011). Global study on homicide. Author. 